\title{
Compound Bieshe Kang'ai inhibits proliferation and induces apoptosis in HCT116 human colorectal cancer cells
}

\author{
Sha Wan ${ }^{1}$, Li Tan ${ }^{1}$, Nan Lei ${ }^{1}$, Yurong Shi ${ }^{1}$, Man He ${ }^{1}$, Meng Zhang ${ }^{1}$, Lijuan Zhou ${ }^{2}$, \\ Liangwen Jin', Xianli Meng ${ }^{1}$, Kui Yang ${ }^{1}$, Haibo $\mathrm{Xu}^{1 \text { * }}$ \\ ${ }^{1}$ Department of Pharmacology, School of Pharmacy, Chengdu University of Traditional Chinese Medicine, ${ }^{2}$ Institute for Chinese \\ Medical Research, Sichuan Academy of Chinese Medical Sciences, Chengdu, China
}

*For correspondence: Email: haibo.xu@cdutcm.edu.cn; Tel: +86-13908197368

Sent for review: 25 August 2018

Revised accepted: 27 October 2018

\begin{abstract}
Purpose: To study the effect of Compound Bieshe Kang'ai (CBK) on proliferation and apoptosis in colorectal cancer cells.

Methods: HCT116 colorectal cancer cells and FHs 74 Int intestinal cells were treated with CBK, followed by determination of cell proliferation with 3-(4,5-dimethylthiazol-2-yl)-2,5-diphenyltetrazolium bromide (MTT) assay. Caspase-9 and caspase-3 activities as well as protein expressions of Bcl-2 and $B A X$, and mRNA levels of caspase-9, caspase-3, Bcl-2 and BAX in HCT116 cells were evaluated, followed by examination of the morphological alterations of HCT116 cells with Hoechst 33342 staining. Results: CBK suppressed proliferation of HCT116 cells in a concentration- and time-dependent pattern, without cytotoxicity to FHs 74 Int cells. CBK also elevated caspase-9 and caspase-3 activities, mitigated protein translation of Bcl-2 and augmented that of BAX. It also enhanced mRNA transcriptions of caspase-9, caspase-3 and BAX, but decreased that of BCl-2 in HCT116 cells in a concentrationdependent manner, as well as induced cancer cell shrinkage, nuclear fragmentation and chromatin condensation.

Conclusion: The findings highlight CBK as a promising therapeutic agent for colorectal cancers, by retarding proliferation and inducing apoptosis in cancer cells.

Keywords: Apoptosis, BAX, BCl-2, Cancer, Caspase, Compound Bieshe Kang'ai, Chromatin condensation, Nuclear fragmentation
\end{abstract}

\begin{abstract}
This is an Open Access article that uses a funding model which does not charge readers or their institutions for access and distributed under the terms of the Creative Commons Attribution License (http://creativecommons.org/licenses/by/4.0) and the Budapest Open Access Initiative (http://www.budapestopenaccessinitiative.org/read), which permit unrestricted use, distribution, and reproduction in any medium, provided the original work is properly credited.

Tropical Journal of Pharmaceutical Research is indexed by Science Citation Index (SciSearch), Scopus, International Pharmaceutical Abstract, Chemical Abstracts, Embase, Index Copernicus, EBSCO, African Index Medicus, JournalSeek, Journal Citation Reports/Science Edition, Directory of Open Access Journals (DOAJ), African Journal Online, Bioline International, Open-J-Gate and Pharmacy Abstracts
\end{abstract}

\section{INTRODUCTION}

Apoptosis is programmed cell death mainly via intrinsic pathway [1]. While apoptotic pathway is activated by various stimuli, family members of B-cell lymphoma 2 are down regulated, which renders pro-apoptotic members to perturb the mitochondria. Subsequently, mitochondria releases cytochrome $c$, resulting in assembly of apoptotic protease-activating factor-1 and procaspase- 9 to form apoptosomes. Consequently, caspase- 9 is activated to cleave downstream targets including executioner caspase- 3 and caspase-7 [2]. 
It is now known that reduced apoptosis and over proliferation are associated with initiation and progression of divers cancer types, which are characterized by impaired apoptotic signaling. To date, a strategy for targeting apoptotic molecules and inducing apoptosis appears to be a therapeutic approach for cancer.

Compound Bieshe Kang'ai (CBK) is a traditional Chinese medicinal formula containing Carapax trionycis (Bie Jia in Chinese), Hedyotis diffusa Willd (Bai Hua She She Cao in Chinese), Rhizoma curcumae (E Zhu in Chinese) and Radix astragali (Huang Qi in Chinese). CBK is broadly utilized in China for medication with high performance for various solid cancers, involving colorectal cancer, hepatoma, gastric cancer and breast cancer. However, the mechanism for the action of $\mathrm{CBK}$ on cancer has so far remained elusive.

Here, the function of $\mathrm{CBK}$ on proliferation and apoptosis in colorectal cancer cells and underlying mechanism of action were investigated, so as to support clinical application of CBK.

\section{EXPERIMENTAL}

\section{Drugs and reagents}

Authentic Chinese medicinal materials of CBK were purchased from Tongrentang (Beijing, China). American Type Culture Collection supplied HCT116 colorectal cancer cells and FHs 74 Int intestinal cells. Caspase-9 assay kit and caspase-3 assay kit were supplied by Beyotime (Nantong, China). The enzyme-linked immunosorbent assay (ELISA) kits for Bcl-2 and $\mathrm{BAX}$ (Bcl-2-associated $\mathrm{X}$ ) were bought from Elabscience Biotechnology (Wuhan, China). QIAGEN (Maryland, USA) provided RNeasy mini kit and quantitative RT-PCR kit.

\section{Preparation of ethanol extract of Compound Bieshe Kang'ai (CBK)}

Briefly, $100 \mathrm{~g}$ of CBK consisting of Carapax trionycis, Hedyotis diffusa Willd, Rhizoma curcumae and Radix astragali in the weight ratio of 1:1:0.9:0.9 were mashed and extracted with $1000 \mathrm{~mL}$ of $85 \%$ ethanol using a refluxing method and filtered, followed by condensation with a rotary evaporator (Bilon, Type RE-52AA, Shanghai, China). Then, the ethanol solvent was evaporated, and the extract was dried at $60{ }^{\circ} \mathrm{C}$, followed by dissolution in $40 \%$ DMSO to a concentration of $1 \mathrm{~g}$ of crude CBK per milliliter. Prior to the tests below, the extract was diluted with cell culture medium to indicated final concentrations containing less than $0.1 \%$ DMSO, and filtrated through a 0.22 microns cellulose ester membrane (Millipore, Massachusetts, USA) for sterilization.

\section{Treatment of cells with CBK}

HCT116 cells were grown with McCoy's 5A medium containing $0.22 \%$ sodium bicarbonate, $10 \%$ FBS (fetal bovine serum), $100 \mu \mathrm{g} / \mathrm{mL}$ of streptomycin, $100 \mathrm{U} / \mathrm{mL}$ of penicillin. FHs 74 Int cells were maintained with Dulbecco's Modified Eagle's Medium containing $10 \%$ of FBS, 30 $\mathrm{ng} / \mathrm{mL}$ epidermal growth factor, $100 \mu \mathrm{g} / \mathrm{mL}$ of streptomycin, $100 \mathrm{U} / \mathrm{mL}$ of penicillin. HCT116 cells or FHs 74 Int cells were treated by CBK at diverse concentrations for various time intervals, followed by the tests as detailed below.

\section{MTT assay of cell proliferation}

After treatment of HCT116 cells or FHs 74 Int cells with $\mathrm{CBK}$ at different concentrations for various durations, MTT solution was aseptically added, followed by 4-hour incubation. After removal of the culture medium, MTT solvent was added, followed by gentle stirring to dissolve MTT formazan crystals, and colorimetric readout with a microplate reader (Thermo Scientific Varioskan Flash, Type 3001) set to $570 \mathrm{~nm}$. The MTT assay was performed twice in quadruplicate.

\section{Caspase activity assay}

Following treatment of HCT116 cells grown in a 6-well plate with CBK for $48 \mathrm{~h}$ at 125, 250 and $500 \mu \mathrm{g} / \mathrm{mL}$, cells were collected for examination of caspase activity with caspase- 9 assay kit and caspase-3 assay kit respectively, in accordance with the user's manual. Shortly, the protein concentration of whole cell lysate from HCT116 cells was determined with Bradford protein assay. Approximately $20 \mu \mathrm{g}$ of lysate were mixed with $2 \mathrm{nmol}$ of Ac-LEHD-pNA (caspase-9) or AcDEVD-pNA (caspase-3) and incubated for 90 min, followed by spectrophotometric measurement of A405 with Thermo Scientific Varioskan Flash (Type 3001). The A405 value was converted to enzyme activity on the basis of the constructed standard curve. The caspase activity assay was performed twice in triplicate.

\section{Protein expression assay}

After 48-hour treatment of HCT116 cells with CBK at 125, 250 and $500 \mu \mathrm{g} / \mathrm{mL}$, cell culture supernatant was retrieved for examining protein levels of Bcl-2 and BAX using ELISA kits for Bcl2 and $B A X$, as per the manufacturer's 
instructions. Basically, samples were added to micro ELISA plates pre-coated with antibodies to $\mathrm{Bcl}-2$ or BAX. After $90-\mathrm{min}$ incubation at $37^{\circ} \mathrm{C}$, biotinylated antibody to Bcl-2 or BAX and avidinhorseradish peroxidase conjugate were added and incubated, followed by addition of the substrate. After incubation for $15 \mathrm{~min}$, the enzyme-substrate reaction was stopped, followed by spectrophotometric determination of $\mathrm{OD}_{450 \mathrm{~nm}}$. Finally, $\mathrm{OD}_{450 \mathrm{~nm}}$ value was converted to protein level according to the standard curve. The assay was conducted triplicately for 2 times.

\section{Quantitative RT-PCR analysis}

After 24-hour treatment with CBK at 125, 250 and $500 \mu \mathrm{g} / \mathrm{mL}$, HCT116 cells were processed for RNA extraction with RNeasy mini kit, followed by reverse transcription (RT) of 500ng of RNA per sample to CDNA with reverse transcription kit. The resulting CDNA was then analyzed using SYBR green PCR kit on iCycler Real-Time PCR System, as per the manufacturer's instructions. Primer sequences were depicted in the table below.

Table 1: Sequence of primers

\begin{tabular}{|c|c|c|}
\hline Gene & Sequence & $\begin{array}{c}\text { PCR } \\
\text { product }\end{array}$ \\
\hline $\begin{array}{l}\text { Caspase } \\
-9\end{array}$ & $\begin{array}{l}\text { 5'- } \\
\text { AGCAGAAAGACCATGGGTT } \\
\text { TGAGG-3' (forward) } \\
\text { 5'- } \\
\text { CCTCCAGGAAACAAAACCT } \\
\text { GGGAA-3' (reverse) } \\
\text { 5'- }\end{array}$ & $197 \mathrm{bp}$ \\
\hline $\begin{array}{l}\text { Caspase } \\
-3\end{array}$ & $\begin{array}{l}\text { GCGTGATGTTTCTAAAGAA } \\
\text { GATCACAGC-3' (forward) } \\
\text { 5'- } \\
\text { GGGTTTTCCAGTTAGACTTC } \\
\text { TACAACGA-3' (reverse) } \\
\text { 5'- }\end{array}$ & 166 bp \\
\hline Bcl-2 & $\begin{array}{l}\text { TGGGGTCATGTGTGTGGAG } \\
\text { A-3' (forward) } \\
\text { 5'- } \\
\text { TAACACAAGGGCATCCCAG } \\
\text { C-3' (reverse) }\end{array}$ & 139 bp \\
\hline BAX & $\begin{array}{l}\text { 5'- } \\
\text { ATGATTGCCGCCGTGGACA } \\
\text { CAG-3' (forward) } \\
\text { 5'- } \\
\text { ACAGGGCCTTGAGCACCAG } \\
\text { TTTG-3' (reverse) }\end{array}$ & 142 bp \\
\hline$\beta$-actin & $\begin{array}{l}\text { 5'- } \\
\text { CCCTGGACTTCGAGCAAGA } \\
\text { GA-3' (forward) } \\
\text { 5'- } \\
\text { ACTCCATGCCCAGGAAGGA } \\
\text { A-3' (reverse) }\end{array}$ & $153 \mathrm{bp}$ \\
\hline
\end{tabular}

$\Delta \mathrm{Ct}$ was calculated by subtracting $\mathrm{Ct}$ of $\beta$-actin, for normalization of mRNA levels in HCT116 cells. The data were shown as fold change relative to the control. The test was performed in duplicate for 3 times.

\section{Staining with Hoechst 33342}

Following 48-h treatment with CBK at 125, 250 and $500 \mu \mathrm{g} / \mathrm{mL}, \mathrm{HCT} 116$ cells were fixed for 10 min with methanol, followed by Hoechst 33342 staining in the dark. After mounting with Antifade PVP medium (Beyotime, Nantong, China), cells were observed with a Leica fluorescence microscope (Type DMI3000B). The test was conducted twice in triplicate.

\section{Statistical analysis}

One-way analysis of variance (ANOVA) and Student's $t$-test were performed with SPSS software for statistical analysis, and the results shown as mean \pm SEM (standard error of the mean). Statistical significance was set at $p<$ 0.05 .

\section{RESULTS}

\section{CBK suppresses proliferation in HCT116 cells}

Except at $31.25 \mu \mathrm{g} / \mathrm{mL}, \quad \mathrm{CBK}$ at other concentrations, including 62.5, 125, 250, 500 and $1000 \mu \mathrm{g} / \mathrm{mL}$, concentration-dependently inhibited the proliferation of HCT116 cells (Figure $1 \mathrm{~A}$ ). Therefore, CBK at 125,250 and $500 \mu \mathrm{g} / \mathrm{mL}$ were selected for subsequent tests. Furthermore, treatment of HCT116 cells with CBK at 250 $\mu \mathrm{g} / \mathrm{mL}$ for $12,24,36$ and $48 \mathrm{~h}$ inhibited proliferation, which was time dependent (Figure 1 $\mathrm{B})$.
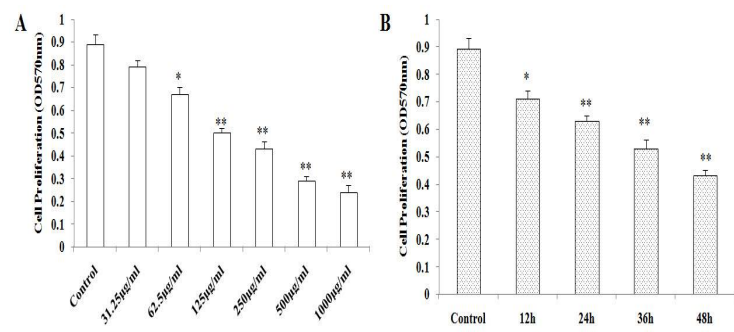

Figure 1: CBK suppresses proliferation in HCT116 cells. ${ }^{*} p<0.05$ and ${ }^{* \star} p<0.01$, verse Control

\section{CBK does not interfere with proliferation in FHs 74 Int cells}

Next, CBK cytotoxicity to normal intestinal epithelial cells was explored. Intriguingly, CBK at all tested concentrations, including $31.25,62.5$, $125,250,500$ and $1000 \mu \mathrm{g} / \mathrm{mL}$, did not suppress the proliferation of FHs 74 Int cells (Figure $2 \mathrm{~A}$ ). Also, viability of FHs 74 Int cells was not affected 
by treatment with CBK at $250 \mu \mathrm{g} / \mathrm{mL}$ for 12,24 , 36 and $48 \mathrm{~h}$ (Figure $2 \mathrm{~B}$ ).

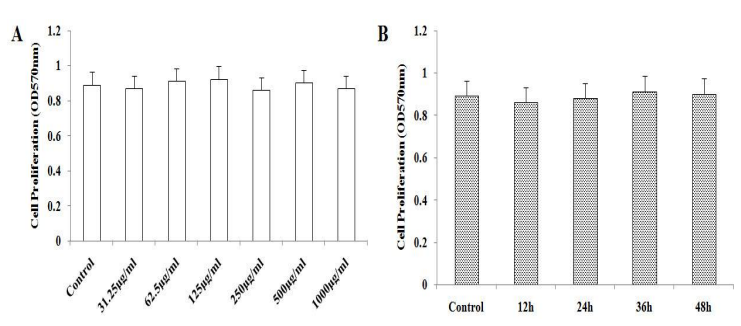

Figure 2: CBK does not interfere with proliferation in FHs 74 Int cells

CBK promotes caspase-9 activity and caspase- 3 activity of HCT116 cells

Treatment of HCT116 cells for $48 \mathrm{~h}$ with CBK at 125,250 and $500 \mu \mathrm{g} / \mathrm{mL}$ enhanced caspase- 9 activity, which was concentration dependent (Figure 3 A). Moreover, CBK at 125, 250 and 500 $\mu \mathrm{g} / \mathrm{mL}$ heightened caspase-3 activity in HCT116 cells in a concentration-dependent pattern (Figure $3 \mathrm{~B}$ ).

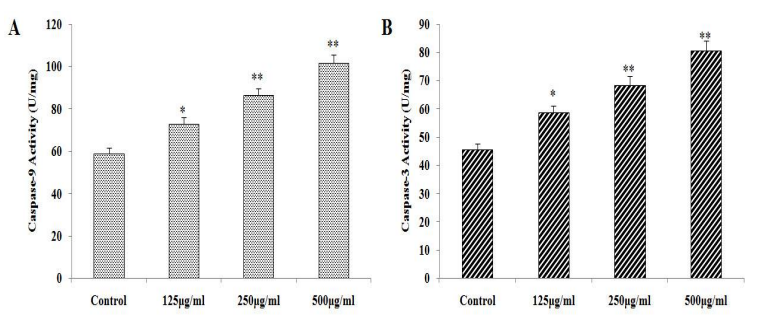

Figure 3: CBK promotes caspase-9 activity and caspase-3 activity. ${ }^{*} p<0.05$ and ${ }^{* *} p<0.01$, verse Control

\section{CBK reduces $\mathrm{Bcl}-2$ protein level and increases the expression of BAX protein in HCT116 cells}

Except at $125 \mu \mathrm{g} / \mathrm{mL}$, the protein translation of Bcl-2 in HCT116 cells was significantly reduced by 48 hour of treatment with CBK at 250 and 500 $\mu \mathrm{g} / \mathrm{mL}$ (Figure $4 \mathrm{~A}$ ). Additionally, 48-hour treatment of HCT116 cells with CBK at 125, 250 and $500 \mu \mathrm{g} / \mathrm{mL}$ increased $B A X$ protein expression, which was concentration dependent (Figure $4 \mathrm{~B}$ ).

\section{CBK influences mRNA transcription of caspase-9, caspase-3, Bcl-2 and BAX in HCT116 cells}

Treatment of HCT116 cells for $24 \mathrm{~h}$ with CBK at 125,250 and $500 \mu \mathrm{g} / \mathrm{mL}$ all drastically increased mRNA transcription of caspase-9 (Figure $5 \mathrm{~A}$ ), caspase-3 (Figure $5 \mathrm{~B}$ ) and BAX (Figure $5 \mathrm{D}$ ). However, Bcl-2 mRNA level of HCT116 cells was sharply decreased by $24 \mathrm{~h}$ of treatment with CBK at 250 and $500 \mu \mathrm{g} / \mathrm{mL}$ (Figure $5 \mathrm{C}$ ). All of these effects of $\mathrm{CBK}$ were concentration dependent.

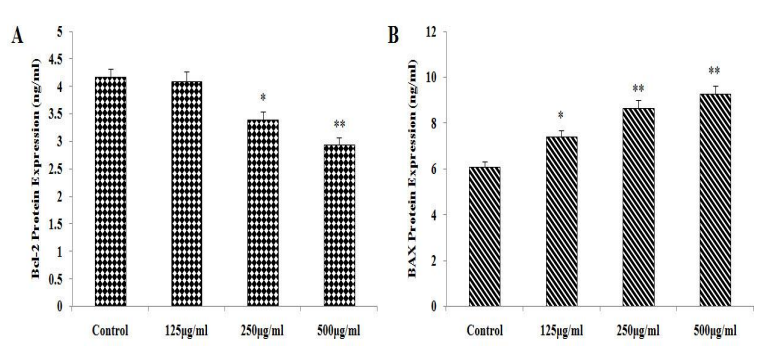

Figure 4: $\mathrm{CBK}$ reduces $\mathrm{Bcl}-2$ protein level and increased BAX protein level. ${ }^{*} p<0.05$ and ${ }^{* *} p<0.01$, verse Control
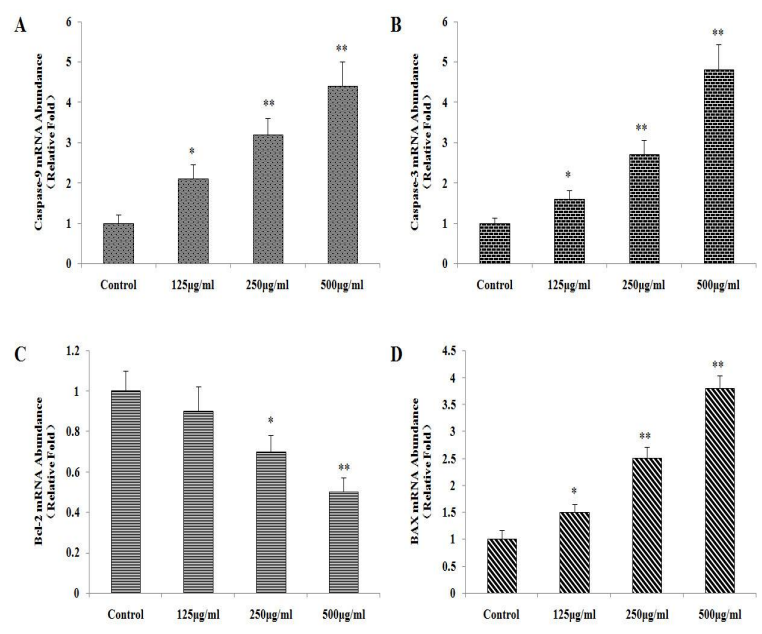

Figure 5: CBK influences mRNA transcription of caspase-9, caspase-3, Bcl-2 and BAX. ${ }^{*} p<0.05$ and ${ }^{* *} p<0.01$, verse Control

\section{CBK induces apoptosis in HCT116 cells}

With Hoechst 33342 staining and fluorescence microscopy, morphologic characteristics for apoptosis of HCT116 cells treated for $48 \mathrm{~h}$ by CBK at 125, 250 and $500 \mu \mathrm{g} / \mathrm{mL}$ were noted. The apoptotic HCT116 cells induced by CBK manifested cell shrinkage, chromatin condensation and nuclear fragmentation, which were at the initial process of apoptosis (Figure 6).
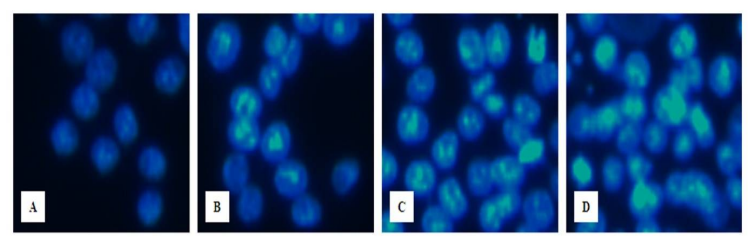

Figure 6: CBK induces apoptosis in HCT116 cells. A, the control; B, CBK at $125 \mu \mathrm{g} / \mathrm{mL}$; C, CBK at 250 $\mu \mathrm{g} / \mathrm{mL} ; \mathrm{D}, \mathrm{CBK}$ at $500 \mu \mathrm{g} / \mathrm{mL}$

Trop J Pharm Res, November 2018; 17(11): 2166 


\section{DISCUSSION}

Mounting evidence reveals that traditional Chinese medicines have some advantages, such as acting on multiple pathological targets and possessing reduced adverse reactions, over modern chemotherapeutic agent for many types of diseases [3,4], particularly involving cancers [5]. Here, we present a Chinese medicinal formula CBK that is efficacious to varieties of cancers in clinical practice, and the underlying mechanism to be delineated.

Firstly, the study showed that CBK suppressed the proliferation in HCT116 cells in a concentration- and time-dependent manner, which coincided with other reports in which Hedyotis diffusa Willd, a Chinese herb of CBK, suppresses colorectal cancer growth through multiple cellular pathways [6], and Radix Astragali that helped carboplatin to inhibit B16 tumor cell growth [7]. Intriguingly, the cytotoxicity of CDK was specific to cancer cells, because CDK did not influence the viability of FHs 74 Int cells, suggesting that CBK may cause less adverse events in clinical settings. In addition, it is reported that Carapax Trionycis inhibits fibrogenesis of activated hepatic stellate cells [8], and Radix Astragali protects against podocyte injury in nephrotic syndrome [9]. The above data demonstrate that $\mathrm{CBK}$ is potentially superior to some chemotherapeutic anti-cancer agents, in terms of causing side effects.

In an attempt to provide novel mechanistic insights into the anti-cancer property of CBK, we set to explore whether or not CBK influenced the activities of apoptosis-mediating caspases, which serve as executioners in apoptotic process by cleaving cellular components. Of direct clinical significance is evidence that human tumors harbor divers point mutations in caspase-9, which renders caspase- 9 inactive and incapable of inducing apoptosis [10]. Here, CBK elevated caspase- 9 activity and caspase- 3 activity in HCT116 cells, as is reported in the study suggesting that Hedyotis diffusa Willd causes apoptosis of A2780 ovarian cancer cells via activation of caspase 9/3 [11].

It is known that the ratio of $\mathrm{Bcl}-2$ level to BAX level plays a crucial role in propagation of apoptotic cascade [12]. In this study, CBK decreased protein translation of $\mathrm{Bcl}-2$ and increased that of BAX in HCT116 cells, which was consistent with another report that Hedyotis diffusa Willd promotes apoptosis of HT-29 colorectal cancer cells by downregulating Bcl-2 level and upregulating BAX level [13].
Additionally, CBK concentration-dependently enhanced the mRNA levels of caspase-9, caspase- 3 and BAX, and lessened Bcl-2 mRNA transcription in HCT116 cells, which further illuminated the mechanism for action of CBK on inducing apoptosis of cancer cells and coincided with other study in which Hedyotis diffusa Willd increases BAX mRNA level and lowers Bcl-2 mRNA level in HepG2 carcinoma cells [14].

Apoptotic cells manifest distinct morphological traits, including chromatin condensation, cell shrinkage and membrane blebbing, accompanied by cleaving of lamins and actin filaments in cytoskeleton by caspases. Then, cellular contents become encased in 'apoptotic bodies', with the translocation of phosphatidylserine from the inside to the outer surface, which promotes phagocytosis of the apoptotic bodies by nearby macrophages [15]. CBK remarkably induced the morphologic changes for early apoptosis in HCT 116 cells, involving cell shrinkage, chromatin condensation and nuclear fragmentation. This was supported by previous reports that Hedyotis diffusa Willd and Rhizoma curcumae of $\mathrm{CBK}$ can induce apoptosis in HL-60 cells, THP-1 cells, SPC-1-A, Bcap37 and HepG2 cancer cells through intrinsic mitochondrial pathway [16].

This pharmacological study presents encouraging experimental evidence, underpinning the clinical utilization of CBK for various cancers, which merits further intense investigations. Efforts should be made to exploit the potency of CBK on extrinsic apoptotic pathway and the influence of CBK on the expression of p53, which can activate the appropriate cellular signaling cascades to execute apoptosis.

\section{CONCLUSION}

The findings show that $\mathrm{CBK}$ lessens proliferation and causes apoptosis in HCT116 cells by regulating the expression and function of some apoptosis-associated genes, such as caspase-9, caspase-3, Bcl-2 and BAX. As reduced apoptosis is a basic aspect of cancer biology and most cytotoxic anticancer therapies ultimately induce apoptosis of malignant cells, CBK with high potency of inducing apoptosis and less adverse effects may be a potent agent for cancers.

\section{DECLARATIONS}

\section{Acknowledgement}

This work was sponsored by National Natural Science Foundation of China (nos. 81173598 
and 81573813), Science and Technology Foundation for Returned Overseas Chinese Scholars of the Ministry of Human Resources and Social Security of China (no. 2011508), Scientific Research Foundation for Returned Overseas Chinese Scholars of the Ministry of Education of China (no. 2013693), Specialized Research Fund for Doctoral Program of Higher Education of the Ministry of Education of China (no. 20115132120010), Natural Science Foundation of Chengdu University of Traditional Chinese Medicine (no. 314-062).

\section{Conflict of interest}

No conflict of interest is associated with this work.

\section{Contribution of authors}

We declare that this work was done by the authors named in this article and all liabilities pertaining to claims relating to the content of this article will be borne by the authors. HBX, KY and XLM conceived and designed the study. SW, LT, $\mathrm{NL}$ and YRS carried out the experiments. $\mathrm{MH}$, MZ, LJZ, LWJ and HBX analyzed the data. SW and HBX wrote the manuscript. All authors read and approved the manuscript for publication.

\section{REFERENCES}

1. Czabotar PE, Lessene G, Strasser A, Adams JM. Control of apoptosis by the BCL-2 protein family: implications for physiology and therapy. Nat Rev Mol Cell Biol 2014; 15(1): 49-63.

2. Croce CM, Reed JC. Finally, An Apoptosis-Targeting Therapeutic for Cancer. Cancer Res 2016; 76(20): 5914-5920.

3. Xu H, Wang D, Peng C, Huang $X$, Ou M, Wang N, Wang $P$, Zhou $L$, Ye $X$. Rabbit sera containing compound danshen dripping pill attenuate leukocytes adhesion to TNF-alpha--activated human umbilical vein endothelial cells by suppressing endothelial ICAM-1 and VCAM-1 expression through NF-kappaB signaling pathway. J Cardiovasc Pharmacol 2014; 63(4): 323-332.

4. Xu $H$, Wu $Q$, Peng $C$, Zhou L. Study on the antiviral activity of San Huang Yi Gan Capsule against hepatitis
$B$ virus with seropharmacological method. $B M C$ Complement Altern Med 2013; 13: 239.

5. Jiao L, Bi L, Lu Y, Wang Q, Gong Y, Shi J, Xu L. Cancer chemoprevention and therapy using chinese herbal medicine. Biol Proced Online 2018; 20: 1.

6. Feng J, Jin Y, Peng J, Wei L, Cai Q, Yan Z, Lai Z, Lin J. Hedyotis diffusa willd extract suppresses colorectal cancer growth through multiple cellular pathways. Oncol Lett 2017; 14(6): 8197-8205.

7. Wu J, Xu H, Zhang L, Zhang $X$. Radix Astragali and Tanshinone Help Carboplatin Inhibit B16 Tumor Cell Growth. Technol Cancer Res Treat 2016; 15(4): 583588.

8. Hu Z, You P, Xiong S, Gao J, Tang Y, Ye X, Xia Y, Zhang $D$, Liu $Y$. Carapax Trionycis extracts inhibit fibrogenesis of activated hepatic stellate cells via TGFB1/Smad and NFKB signaling. Biomed Pharmacother 2017;95: 11-17.

9. Sai YP, Sun YC, Chen $X X$, Luo $X$, Liu J, Cui WJ. Protective effect of astragalosides from Radix Astragali on adriamycin-induced podocyte injury. Exp Ther Med 2018; 15(5): 4485-4490.

10. Fiandalo MV, Kyprianou N. Caspase control: protagonists of cancer cell apoptosis. Exp Oncol 2012; 34(3): 165175.

11. Zhang L, Zhang J, Qi B, Jiang G, Liu J, Zhang P, Ma Y, $\mathrm{Li} W$. The anti-tumor effect and bioactive phytochemicals of Hedyotis diffusa willd on ovarian cancer cells. J Ethnopharmacol 2016; 192: 132-139.

12. Gomez-Fernandez JC. Functions of the C-terminal domains of apoptosis-related proteins of the Bcl-2 family. Chem Phys Lipids 2014; 183: 77-90.

13. Lin J, Li Q, Chen H, Lin H, Lai Z, Peng J. Hedyotis diffusa Willd. extract suppresses proliferation and induces apoptosis via IL-6-inducible STAT3 pathway inactivation in human colorectal cancer cells. Oncol Lett 2015; 9(4): 1962-1970.

14. Li YL, Zhang J, Min D, Hongyan Z, Lin N, Li QS. Anticancer Effects of 1,3-Dihydroxy-2Methylanthraquinone and the Ethyl Acetate Fraction of Hedyotis Diffusa Willd against HepG2 Carcinoma Cells Mediated via Apoptosis. PLoS One 2016; 11(4): e0151502

15. Kumar M, Kaur V, Kumar S, Kaur S. Phytoconstituents as apoptosis inducing agents: strategy to combat cancer. Cytotechnol 2016; 68(4): 531-563.

16. Lu JJ, Dang YY, Huang M, Xu WS, Chen XP, Wang YT. Anti-cancer properties of terpenoids isolated from Rhizoma Curcumae--a review. J Ethnopharmacol 2012; 143(2): 406-411. 